\title{
Life Expectancy In Zimbabwe: An Analysis Of Five Decades
}

\author{
Genius Murwirapachena, Nelson Mandela Metropolitan University, South Africa
}

Courage Mlambo, University of Fort Hare, South Africa

\begin{abstract}
Great inconsistencies have been observed in life expectancy dynamics in Zimbabwe over the past decades. Contradictions exist among Zimbabweans where some believe that people used to live longer during the colonial era than they live now. Such beliefs have been exacerbated by the recent economic woes that ensued in the country. Dynamics in the Zimbabwean life expectancy patterns have seen male Zimbabweans outliving their female counterparts since the year 2000. Such an alteration contradicts general world life expectancy trends where females commonly live longer than males. This paper analyses trends in the Zimbabwean life expectancy over the period 1970 to 2012. The ordinary least squares method is used to examine the impact of economic growth, inflation, increase in agriculture land, population growth and the dependency ratio on life expectancy in Zimbabwe. Empirical results from this study revealed that economic growth, inflation and population growth have a positive relationship with life expectancy while increases in both agricultural land and the dependency ratio have negative effects on life expectancy in Zimbabwe.
\end{abstract}

Keywords: Life Expectancy; Economic Growth; Zimbabwe

\section{INTRODUCTION}

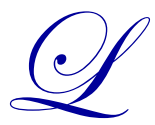

ife expectancy has been progressively increasing in most parts of the world over the recent successive decades. Reasons for such increases include access to better health facilities, improved water facilities, better sanitation, literacy and technological advancements (World Health Organization (WHO), 2005).

Even though levels of life expectancy increased across the globe over the decades, enormous discrepancies exist between developed and developing nations. Developed nations have higher life expectancies compared to the less developed ones. Mathers et al. (2001) used the health life expectancy (DALE) tool to reveal that Japan had the highest average life expectancy of 74.5 years at birth in 1999. This sharply contrasted with the bottom ten countries (all developing sub-Saharan) which had average health life expectancies of less than 35 years at birth (Mathers, et al., 2001). Amongst these countries is Zimbabwe which has had a poor life expectancy record since the onset of the 2000s. Life expectancy in Zimbabwe has exhibited gradually falling patterns since the year 2000 although it later rose after the formation of the unity government in 2009. The issue of life expectancy is contemporarily topical in Zimbabwe because by the year 2000, the country had an average life expectancy of about 43.9 years (World Bank, 2013) and was among the bottom ten in terms of the WHO (2005) average life expectancies. Even though the average life expectancy slightly grew from about 43.9 years in 2000 to about 51.1 years in 2009 then 55.9 in 2011 (World Bank, 2013), the increase was slightly lower relative to world trends. The sluggish increase in life expectancy was mainly due to Zimbabwe's economy which has been deteriorating without any sign of improvement and the HIV and AIDS epidemic, among other reasons.

What is also striking about the life expectancy trends in Zimbabwe is the poor life expectancy record for females in the past decade. Contrary to popular belief that the life expectancy of females is always higher than that of males, the life expectancy of Zimbabwean females has been, in the past decade, lower than that of males. Between the years 2001 to 2012, the average life expectancy for male Zimbabweans according to the World Bank (2013) was about 46.9 years while the average for women was about 45.6 years. Zimbabwe's situation was contrary to the world trends explained by Barford et al. (2006) who suggested that even in the poorest countries women can expect to outlive men. 
Life expectancy is one of the most important indicators of a country's health status because it reflects the overall mortality of a country's population. Accordingly, declining life expectancies reflect some problems in a country's health sector. The issue of life expectancy in Zimbabwe is an area of concern because the country has had a declining trend since the year 2000. The fact that life expectancy is an indicator of public health, an analysis of the factors that influences it and also an examination of the causes of its poor record in Zimbabwe is important for public health policy and for the general welfare. This forms the objective of this study, that is, to examine the relationship between life expectancy and selected socio-economic variables in Zimbabwe. The study is structured as follows; after this introductory section is section two which gives an overview of life expectancy in Zimbabwe. The third section reviews the existing empirical literature and it is followed by the fourth section which highlights the methodology used in this paper. The fifth section discusses empirical results and the sixth and final section concludes the study.

\section{AN OVERVIEW OF LIFE EXPECTANCY IN ZIMBABWE}

The main focus of this section is to give an overview of the trends and dynamics of life expectancy in Zimbabwe for the past five decades. The section is sub-divided into four parts; the first part reviews the life expectancy trends, the second part presents a comparison of Zimbabwean life expectancy to selected SADC countries, the third part compares the male life expectancy to female life expectancy in Zimbabwe and the fourth part reviews life expectancy and economic growth trends in Zimbabwe.

\section{Trends In Zimbabwe's Life Expectancy (1970 To 2012)}

Over the recent decades, significant inconsistencies have been witnessed in Zimbabwe's life expectancy patterns. While most countries in the world recorded upward trends in average life expectancy, Zimbabwe recorded erratic trends in life expectancy. In the two decades leading to 2009, life expectancy in Zimbabwe dropped significantly (see Figure 1) as a result of several factors. Such factors include the blowout of HIV, AIDS and other deadly diseases (Griffith, 2001 and Chapman, et al., 2006), deteriorating economic activity and lack of access to medical facilities (Yikoniko, 2012), as well as the viral spread of poverty in the country as explained in Mahfuz (2008). Figure 1 illustrates trends in the Zimbabwean life expectancy for five decades (1970 to 2012).

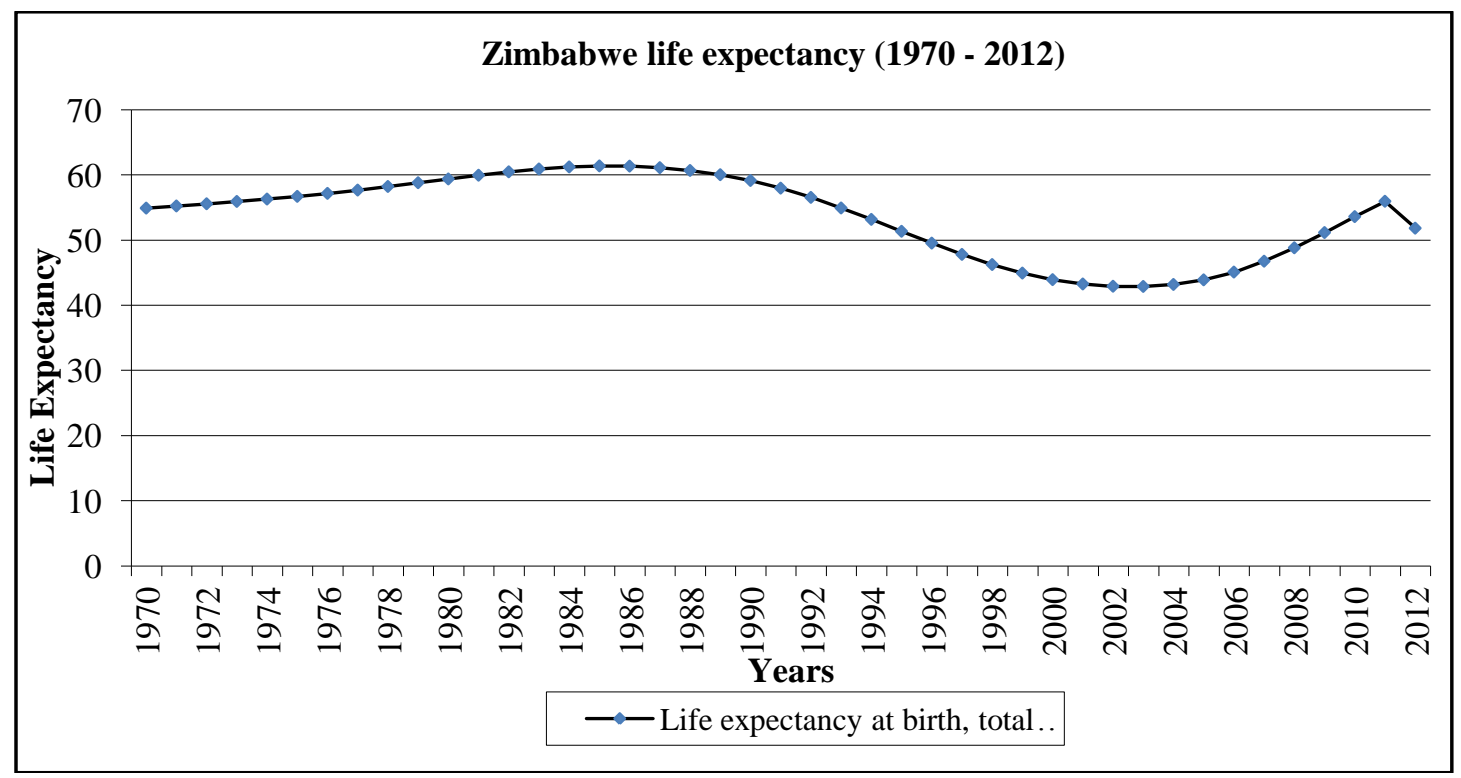

Source: Own Graph With Figures From The World Bank (2013)

Figure 1. Zimbabwe Life Expectancy Over The Years 1970 To 2012

As shown in Figure 1, during the 1970 to 1979 decade, life expectancy in Zimbabwe (then Rhodesia) averaged 56.6 years. It increased to an average of 60.6 years in the 1980 to 1989 decade. This was the first decade of 
an independent Zimbabwe and the Mugabe led regime had great devotion and commitment to serve the country and to improve the standard of living for Zimbabweans. Substantial economic growth rates were recorded in this decade except for 1984 where an annual economic decline of -1.9 per cent was recorded (World Bank, 2013). During the 1990 to 1999 decade, life expectancy dropped to an average of 52.2 years. This drop from the previous decade's average of 60.6 years could be attributed to several factors including the complacency of the Mugabe regime which had been in power for quite a long time, effects of HIV and AIDS discovered in the previous decade, the 1992 drought which impacted negatively on the lives of Zimbabweans, among other reasons.

Life expectancy in Zimbabwe dropped to the lowest average over the decades in the 2000 to 2009 decade where Zimbabweans were on average expected to live for up to 45.2 years. This histrionic decline in life expectancy may be attributed to the deterioration of the standard of living which was a result of a decline in the country's economic activities. The Zimbabwean economy experienced a meltdown during this period. Hyperinflation coupled with poor economic management policies brought the Zimbabwean economy to near standstill. As a result of this, there were basic food shortages and most retail commodities were found only in the streets. The socio-economic sector was also heavily affected by the adverse economic conditions in Zimbabwe. There was a huge decline in the education standards and the health sector nearly collapsed. This contributed significantly to the declining life expectancy.

However, between 2010 and 2012, life expectancy in Zimbabwe increased to an average of about 53.9 years. On average, Zimbabweans now lived about 8 years longer in this decade relative to the previous decade. This improvement could be credited to the formation of a Government of National Unity (GNU) formed between the Zimbabwe African National Union-Patriotic Front (ZANU PF) and the two factions of the Movement for Democratic Change (MDC). The coalition of these political parties to form a government of national unity brought stability and some sense of hope in Zimbabwe. The use of multiple foreign currencies, to a larger extent, also resuscitated the economy which was on the brink of total collapse at the time of the formation of the unity government. Accordingly, state hospitals, shops and other businesses reopened and basic food staffs were back on the market. This improved the overall mortality of the Zimbabwean population.

\section{A Comparison Of Zimbabwean Life Expectancy To Selected SADC Countries}

Over the 40 years analysed in this study, 1985 recorded the highest average life expectancy of 61.4 years while 2002 and 2003 recorded the lowest average life expectancy of 42.9 years. To gain more insight into trends in Zimbabwean life expectancy, it is imperative to compare the country to its neighbouring countries in the Southern African Development Community (SADC). Table 1 shows comparisons of the Zimbabwean average life expectancies to its selected SADC partner countries.

Table 1. Comparison Of Zimbabwean Life Expectancy To Selected SADC Countries

\begin{tabular}{lcccc}
\hline & $\mathbf{1 9 7 0} \mathbf{- 1 9 7 9}$ & $\mathbf{1 9 8 0 - 1 9 8 9}$ & $\mathbf{1 9 9 0} \mathbf{- 1 9 9 9}$ & $\mathbf{2 0 0 0} \mathbf{- 2 0 0 9}$ \\
\hline Zimbabwe & 56.6 & 60.6 & 52.2 & 45.2 \\
South Africa & 54.5 & 59.5 & 60.8 & 53.0 \\
Botswana & 57.5 & 62.5 & 58.0 & 47.5 \\
Ethiopia & 43.7 & 44.7 & 49.1 & 56.2 \\
Mozambique & 41.2 & 43.0 & 45.5 & 47.9 \\
Congo. D.R & 45.0 & 46.8 & 46.7 & 47.6 \\
Malawi & 42.4 & 45.8 & 46.7 & 48.9 \\
\hline
\end{tabular}

Source: Own Table With Figures From The World Bank (2013)

Except for the 2000 to 2009 decade, Zimbabwe has been doing fairly well relative to most of its selected SADC partners in terms of life expectancy. Table 1 shows that in the first two decades (1970 to 1989), Zimbabweans lived longer than South Africans, Ethiopians, Mozambicans, Congolese and Malawians. In those two decades, Zimbabwe was only second to Botswana which topped the region with respective averages of 57.5 years and 62.5 years, compared to Zimbabwe's 56.6 years and 60.6 years. However, life expectancy in Zimbabwe dropped significantly in the succeeding decades. Zimbabwe had the least average life expectancy compared to all the selected SADC partners in the 2000 to 2009 decade. Imperative to note is that Zimbabwe and Botswana are the only countries with uninterrupted downward trends in their average life expectancies in decades since 1980. 


\section{Male Versus Female Life Expectancy In Zimbabwe (1970 To 2012)}

Improving the status of women has been at the centre of most countries in the recent years. Aspects on women's status such as their educational status, economic status and reproductive autonomy prove to be important predictors of female life expectancy (Williamson and Boehmer, 1997). Generally in the world, empowered women live longer than males. This has been the case in Zimbabwe until 2000 when according to Mathers et al. (2001) the country was amongst the only six countries where women live less than men. Development indicators released by the World Bank (2013) show that women in Zimbabwe live less than men since the year 2001. This is quite surprising since women lived longer than men in the preceding decades. More disheartening is that Zimbabwe is among the only six countries where women live less than men in the recent years. Trends in Zimbabwe's male and female life expectancies for the period 1970 to 2012 are shown in Figure 2.

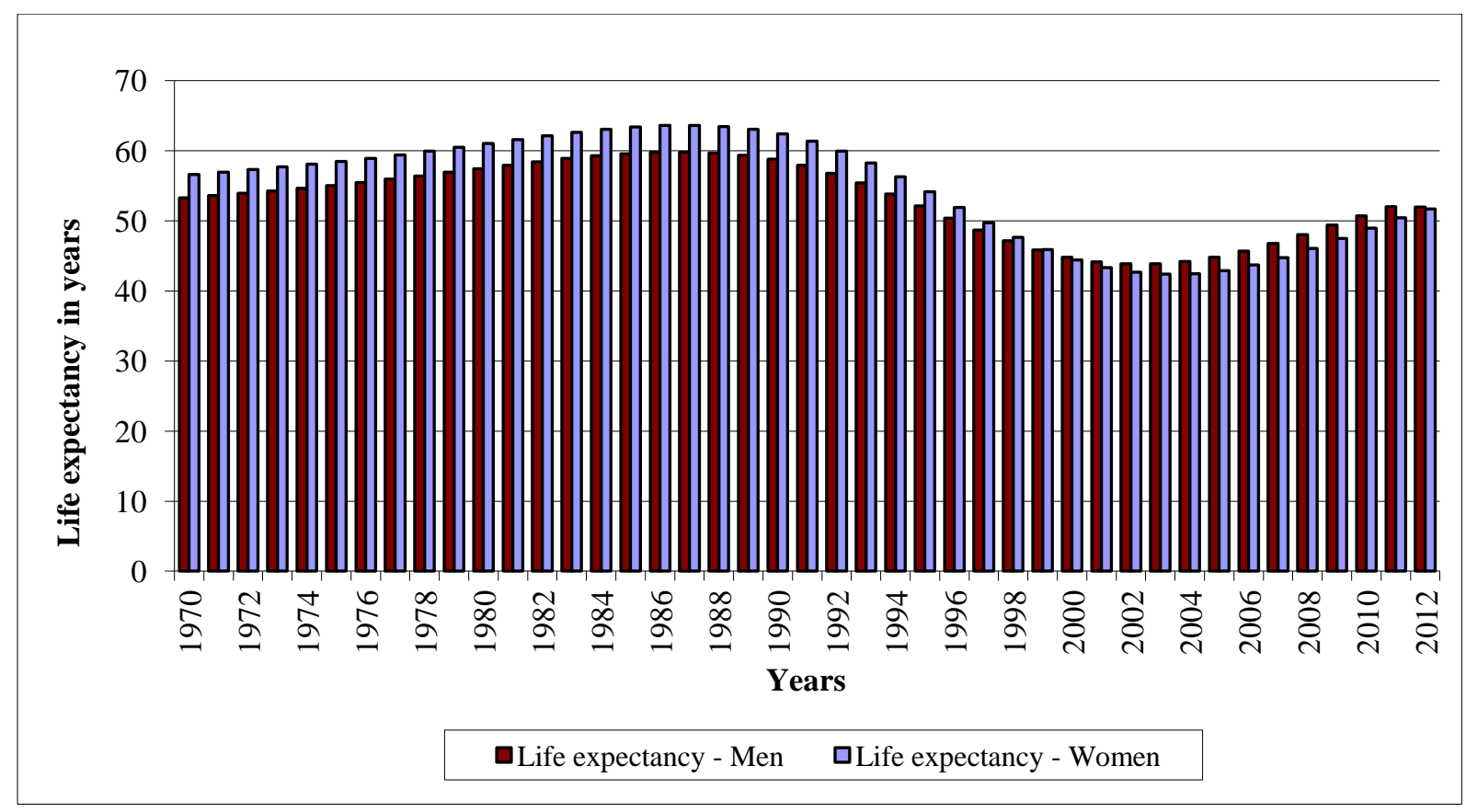

Source: Own Graph With Figures From The World Bank (2013)

Figure 2. Male Versus Female Life Expectancy In Zimbabwe (1970 To 2012)

As shown in Figure 2, female life expectancy in Zimbabwe exceeded male life expectancy for the years 1970 to 1999 . From the year 2000 onwards, male Zimbabweans lived longer than their female counterparts. To gain more insight into the male versus female life expectancy comparisons, this section presents averages for the past five decades. In the first decade (1970 to 1979) men had an average life expectancy of 54.9 years which was less than women's average of 58.4 years. In the subsequent decade (1980 to 1989), average life expectancy increased to 59.0 years for males and 62.8 years for females. Reasons to these improvements are more linked to the robust economic policies and political stability in the country after independence. Even though the aggregate life expectancy declined in the succeeding decade (1990 to 1999), male Zimbabwean had an average life expectancy of 52.7 years, which was less than the female average of 54.7 years.

A complete turn of events was witnessed in the 2000 to 2009 decade when males had an average life expectancy of 45.6 years, which was higher than women's average of 44.0 years. Possible reasons for the drastic decline in women's life expectancy include their loss of economic status as a result of harsh economic and political environments in the country. The economic hardships and inaccessibility to proper medical facilities exposed women to diseases and other catastrophes as cited in Hallett et al. (2011). However, the formation of the GNU in 2009 brought some economic progress and saw average life expectancy improving to 51.6 years for male and 50.4 years for females in the years 2010 to 2012. This improvement is however dissatisfactory since women's life expectancy was still lower than men's. 


\section{Life Expectancy Versus Economic Growth In Zimbabwe}

The causality between life expectancy and economic growth as explained by Judge (1995) inspires the need to analyse the link between the two in the case of Zimbabwe. To gain more intuition in the life expectancy issue, it is consequently vital to assess the trend relationship between the variable and economic growth. Figure 3 shows trends in both life expectancy and economic growth in Zimbabwe for the period 1970 to 2012.

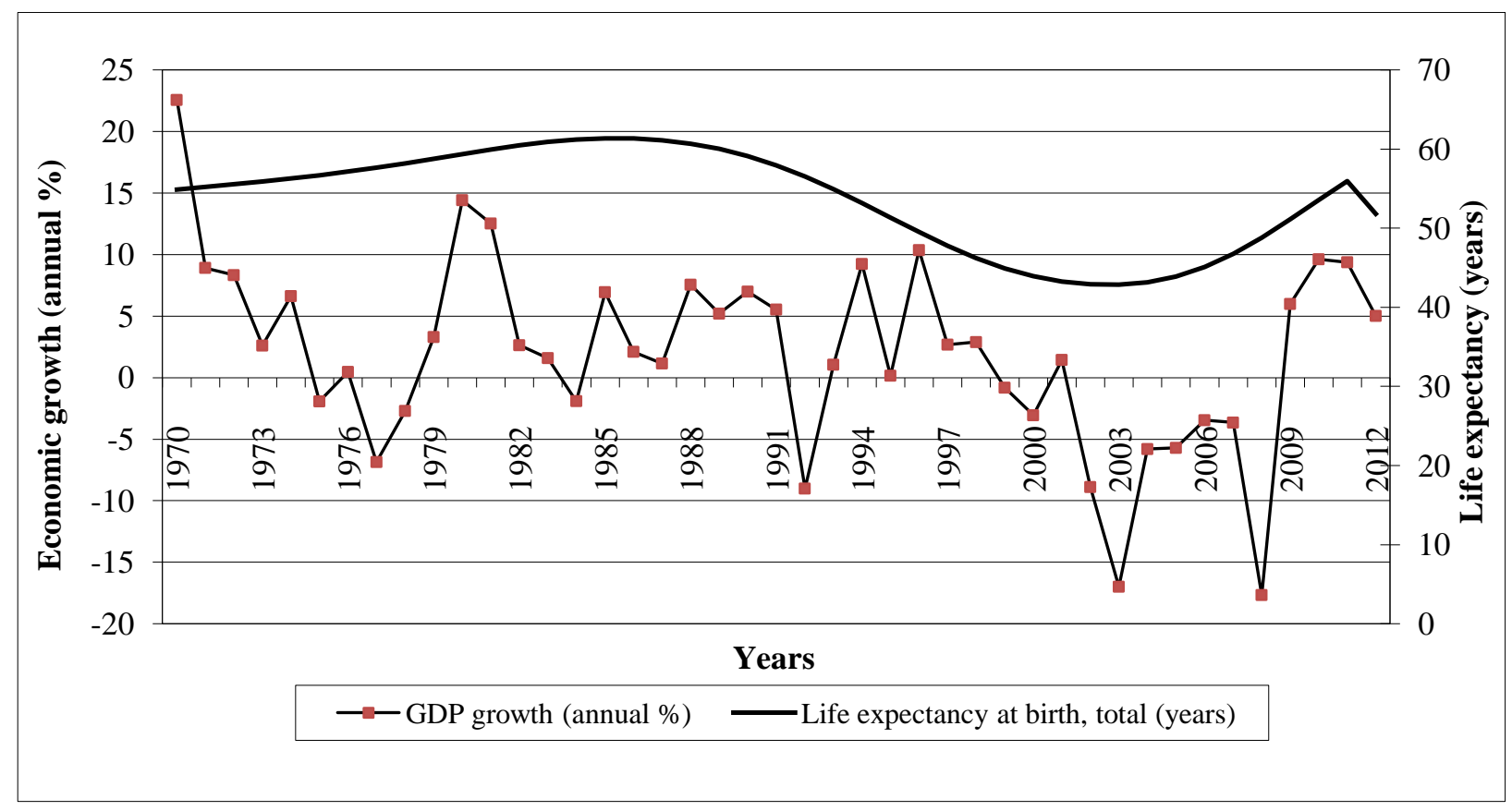

Source: Own Graph With Figures From The World Bank (2013)

Figure 3. Life Expectancy And Economic Growth In Zimbabwe (1970 To 2012)

Figure 3 revealed that periods of high economic growth recorded higher life expectancies while periods of economic decline recorded lower life expectancies. The period 1999 to 2008 recorded massive economic decline which could also have affected life expectancy as the country recorded its least levels of life expectancy during this period. This relationship will be empirically tested in the fifth section.

The statement that Zimbabweans used to live longer during the colonial era is a complete fallacy assumed only by people who are dissatisfied with the current regime. The five decade analysis of life expectancy conducted in this section revealed that Zimbabweans lived longer in the first decade after independence relative to the preceding decade. Decades subsequent to the 1980 to 1989 decade recorded a decline in life expectancy. The least average life expectancy for the study period was recorded in the 2000 to 2009 decade. This section also revealed that Zimbabweans lived longer than residents of other SADC countries except in the 2000 to 2009 decade when Zimbabweans lived less than residents of all the selected SADC countries. It was also shown in this section that female Zimbabweans lived longer than their male counterparts until 2000 when male Zimbabweans started to outlive female Zimbabweans. This section also analysed the relationship between economic growth and life expectancy. It was revealed that periods of economic growth recorded higher levels of life expectancy while periods of economic decline recorded lower levels of life expectancy.

\section{LITERATURE REVIEW}

A plethora of empirical literature on life expectancy and its determinants in both developed and less developed countries (LDCs) exist. Most of these used cross sectional data to analyse the determinants of life expectancy in panelled countries. Literature on LDCs includes studies by Williamson and Boehmer (1997), Lin et al. (2005), Mahfuz (2008) as well as Bergh and Nilsson (2010), among others. Empirical literature on developed 
countries includes studies by Barlow and Vissandjee (1999) as well as Shaw et al. (2005). Even though limited literature exists on life expectancy in Zimbabwe, some notable contributions were made from studies such as the works of Griffith (2001), Chapman et al. (2006) and Hallett et al. (2011).

Williamson and Boehmer (1997) used multiple regression and cross-sectional samples varying from 40 to 97 countries to examine female life expectancy, gender stratification, health status, and level of economic development in LDCs. The study assessed the utility of gender stratification theory in accounting for cross-national differences in female life expectancy in LDCs. Using an incremental model building strategy, evidence was presented that aspects of women's status such as educational status, economic status and reproductive autonomy had a positive effect on female life expectancy. Even though the study can be commended for assessing the determinants of life expectancy in less developed countries its focus was only limited to women.

In a male and female inclusive study, Bergh and Nilsson (2010) used different estimation techniques and sample groupings to analyse the relationship between three dimensions (economic, social, and political) of globalization and life expectancy in LDCs. The study examined a panel of 92 countries using data for the period 1970 to 2005. It was found that economic globalization has a robust positive effect on life expectancy, even when controlling for income, nutritional intake, literacy, number of physicians, and other factors. The study also revealed that political and social globalizations have no such robust effects. Results from this study are compatible with most LDCs whose living conditions and expectancy improve upon attaining economic globalization. Globalizing the politics and social aspects of an LDC would leave it vulnerable, eroding both its stability and social fabrics.

A more specific analysis was used by Lin et al. (2005) who applied linear mixed models to examine the political and social determinants of life expectancy in LDCs. Using data for 119 countries for the period 1970 to 2004, life expectancy was regressed against economic growth, literacy, nutritional status and political regime. The study concluded that even though the short-term impact of democracy on increasing life expectancy is relatively small when compared to that of socioeconomic factors such as economy and nutritional status, the long-term impact of democracy increases over time and should not be underestimated. Findings from the study suggested that in Africa, where 35 countries were still not categorized as democracies as of 2004, any campaign to prolong life expectancies should include goals for political democratization in addition to economic development and nutritional improvements. The study is applicable to Zimbabwe which is not yet a democracy and has serious issues on economic growth and undernourishment even though its literacy is relatively high.

Shaw et al. (2005) used the Ordinary Least Squares method to examine the determinants of life expectancy in 29 of the 30 OECD countries. Health data for the period 1960 to 1999 was used and an aggregate life expectancy production function was considered. The study revealed that pharmaceutical consumption has a positive effect on life expectancy at middle and advanced ages but is sensitive to the age distribution of a given country. The study further discovered that doubling annual pharmaceutical expenditures adds about one year of life expectancy for males aged 40 and slightly less than a year of life expectancy for females aged 65. Results for lifestyle inputs were also presented into the life expectancy production function. It was revealed that decreasing tobacco consumption by about two cigarettes per day or increasing fruit and vegetable consumption by 30 per cent increased life expectancy by approximately one year for 40-year-old females. Even though results from this study can be relevantly applicable, the sample countries examined are far more developed economically relative to Zimbabwe. This therefore renders results of this study less applicable to our country of interest where health systems are drastically poor and less advanced.

Chapman et al. (2006) examined the burden of disease in Zimbabwe as measured by disability-adjusted life years lost. The study ranked health problems contributing most to the burden of disease in Zimbabwe using disability-adjusted life years as the population health measure. Population size and total number of deaths by age and sex were taken from a nationwide census. The cause of death pattern was determined based on data from the Vital Registration System, which was adjusted for under-reporting of human immunodeficiency virus (HIV) and reallocation of ill-defined causes. Non-fatal disease figures were estimated based on local disease registers. From the information collected, HIV infection emerged as the single most serious public health problem in Zimbabwe responsible for 49 per cent of the total disease burden. A quarter of the total burden of disease was attributed to morbidity rather than premature mortality. The share of the disease burden was similar in females and males. The 
study developed plausible estimates of the size and significance of major health problems in Zimbabwe. Disease patterns in Zimbabwe differed substantially from regional estimates for sub-Saharan Africa justifying the need for countries to develop their own burden of disease estimates. This study gives some insight in the major causes of death in Zimbabwe. Although it lacks a more direct approach on life expectancy and its other determinants beside diseases, the study is hugely relevant to this study.

Except for the work of Chapman et al. (2006), all the studies mentioned in this section examined issues of life expectancy in countries panelled together. Grouping countries together may be critical because different conditions exist in different countries, even those sharing geographical borders. This paper is therefore relevant because it will examine the determinants of life expectancy in Zimbabwe as an individual country.

\section{METHODOLOGY}

This study uses the ordinary least squares method to estimate the determinants of life expectancy in Zimbabwe. Data used is first tested for stationarity using the Augmented Dickey-Fuller (ADF) and the PhillipsPerron (PP) tests. Diagnostic checks are also performed to test for heteroskedacity (White test) and serial correlation (Lagrange Multiplier). The study performs the Ramsey RESET and the CUSUM tests for stability in the model.

\section{Model Specification}

The study adopts the work of Lin et al. (2005) who expressed life expectancy as a function of economic growth, literacy, nutritional status and political regime in 119 LDCs for the period 1970 to 2004 . The model will be modified to examine the impact of economic growth and other socio-economic variables on life expectancy in Zimbabwe. In this study, life expectancy will be modelled as a function of economic growth, inflation, agriculture land, population growth and the dependency ratio in Zimbabwe as expressed in Equation 1:

$$
\text { EXPECT }{ }_{t}{ }_{0}+{ }_{1} G D P_{t}+{ }_{2} C P I_{t}+{ }_{3} A G R_{t}+{ }_{4} P O P_{t}+{ }_{5} D E P_{t}+{ }_{t}
$$

where:

EXPECT $=$ Life expectancy at birth, total (years). Life expectancy is the number of years a new-born infant would live if prevailing patterns of mortality at the time of its birth were to stay the same through the rest of its life.

GDP = GDP growth (annual \%), a measure of economic growth. High rates of economic growth are assumed to have a positive impact on the general wellbeing of residents of a particular country and thus a positive relationship with life expectancy.

CPI = Annual change in the consumer price index $(2005=100)$, an instrument for inflation. This variable was selected because the continuous increase in the general price levels in an economy determines the affordability of basic commodities which affect the standard of living and possibly the life expectancy. Inflation is expected to have a negative relationship with life expectancy.

AGR = Growth in agricultural land (\% of land area) per annum. Agricultural land is considered a vital resource to the economic success of Zimbabwe. However, in newly resettled areas there is no basic infrastructure, no hospitals, clinics and the roads are in bad shape. In addition to this, there is limited access to piped water and this makes these areas to be prone to cholera, dysentery and other water-borne diseases. This, then, increases the mortality rate of these communities. Accordingly, this variable (AGR) is expected to have a negative relationship with life expectancy.

$\mathbf{P O P}=$ Growth in total population per year. Population size has to an extent effects on the access and distribution of a country's resources which directly impacts on the standard of living. Less populated areas generally have greater access to resources relative to densely populated areas. Due to the shortage of doctors in Zimbabwe, an increase in population increases the doctor to patient rate. This is undesirable as it negatively affects life expectancy. Accordingly, this variable is expected to have a negative relationship with life expectancy. 
DEP = Annual changes in the age dependency ratio ( $\%$ of working-age population). The number of dependents an economically active person has indicates the financial burden of that particular person. Extended families are common in Zimbabwe affecting the general living standards and conditions of families. This variable is expected to have a negative relationship with life expectancy.

\section{DATA ISSUES}

This study uses annual time series data for the period 1970 to 2012 . The data were obtained from the World Bank electronic database, 2013 Development Indicators. Due to incomplete data on CPI from the World Bank database, CPI data for the period 2007 to 2012 were obtained from the electronic database of the Reserve Bank of Zimbabwe.

\section{EMPIRICAL RESULTS}

\section{Unit Root Tests}

As explained earlier, the data used in this study is tested for stationarity using the Augmented DickeyFuller (1979) and the Phillips-Perron (1988) unit root tests. Stationarity tests are done both in levels and in first difference. Unit root test results are presented in Table 2.

Table 2. Unit Root Tests

\begin{tabular}{lll|cc}
\hline & \multicolumn{2}{c|}{ Augmented Dickey-Fuller (ADF) } & \multicolumn{2}{c}{ Phillips Peron (PP) } \\
\hline EXPECT & \multicolumn{1}{c|}{ Level } & $\mathbf{1}^{\text {st }}$ Difference & Level & $\mathbf{1}^{\text {st }}$ Difference \\
\hline GDP & -1.425307 & $-2.917067 *$ & -1.061135 & -1.9988064 \\
CPI & $-3.455508^{* *}$ & $-5.956830^{* * *}$ & $-4.618704 * * *$ & $-9.425794 * * *$ \\
AGR & $-4.526460^{* * *}$ & $-7.449393 * * *$ & $-6.481864 * * *$ & $-14.25241^{* * *}$ \\
POP & -1.564007 & $-5.226641 * * *$ & $-3.702662^{* * *}$ & $-14.70656^{* * *}$ \\
DEP & $-4.003871 * * *$ & $-4.130833^{* * *}$ & -1.160264 & -0.703892 \\
\hline $1 \% * * *$ & $-4.460185 * * *$ & $-5.783041^{* * *}$ & -1.434105 & -1.536876 \\
$5 \% * *$ & -3.5973 & -3.6019 & -3.5930 & -3.5973 \\
$10 \% *$ & -2.9339 & -2.9358 & -2.9320 & -2.9339 \\
\hline$* * * * *$ and & -2.6048 & -2.6059 & -2.6039 & -2.6048 \\
\hline
\end{tabular}

$* * *, * *$ and $*$ represent significance levels at $1 \%, 5 \%$ and $10 \%$ respectively.

Except for life expectancy (EXPECT) and growth in agriculture land as a percentage of total land (AGR) which are non-stationary, all the variables are stationary in levels at 1 per cent significance level and 5 per cent significance level for economic growth. However, when first differenced, all the data series are stationary at 1 per cent significance level except for EXPECT which is stationary at 10 per cent. It can therefore be concluded that all data series are integrated of order one, I(1).

\section{Presentation Of Regression Results}

The actual relationship and magnitude of effect of the selected explanatory variables on life expectancy is estimated using the ordinary least squares (OLS) method. Table 3 presents results of the life expectancy model as estimated by the OLS method. 
Table 3. Estimation Output

\begin{tabular}{|c|c|c|c|c|}
\hline \multicolumn{5}{|c|}{ Dependent Variable: EXPECT } \\
\hline \multicolumn{5}{|c|}{ Method: Least Squares } \\
\hline \multicolumn{5}{|c|}{ Date: $12 / 27 / 13$ Time: $20: 47$} \\
\hline \multicolumn{5}{|l|}{ Sample: 19702012} \\
\hline \multicolumn{5}{|c|}{ Included observations: 43} \\
\hline Variable & Coefficient & Std. Error & t-Statistic & Prob. \\
\hline $\mathrm{C}$ & 45.49399 & 0.977060 & 46.56212 & 0.0000 \\
\hline GDP & -0.045235 & 0.053751 & -0.841565 & 0.4054 \\
\hline CPI & $1.39 \mathrm{E}-06$ & $6.78 \mathrm{E}-07$ & 2.049684 & 0.0475 \\
\hline AGR & -2.673434 & 0.643875 & -4.152104 & 0.0002 \\
\hline POP & 4.079958 & 0.293192 & 13.91567 & 0.0000 \\
\hline DEP & -0.965832 & 0.453989 & -2.127434 & 0.0401 \\
\hline R-squared & 0.901418 & Mean dependent var & & 53.66504 \\
\hline Adjusted R-squared & 0.888096 & S.D. dependent var & & 6.255002 \\
\hline S.E. of regression & 2.092422 & Akaike info criterion & & 4.443309 \\
\hline Sum squared resid & 161.9945 & Schwarz criterion & & 4.689058 \\
\hline Log likelihood & -89.53115 & F-statistic & & 67.66467 \\
\hline Durbin-Watson stat & 1.867022 & Prob(F-statistic) & & 0.000000 \\
\hline
\end{tabular}

The high Adjusted R-squared which measures the closeness of fit in the regression model as well as the statistical fitness of the model to the data used is 0.888096 (approximately 89 per cent). This suggests that the data used in this study are robust and the model used is statistically fit. All variables are statistically significant in explaining life expectancy except for economic growth with a t-statistic that is less than 2. The Durbin-Watson statistic of 1.867022 suggests the absence of positive serial correlation. The absence of serial correlation in the data will further be tested in diagnostic checks later in this study. Empirical results from table 3 can be substituted in Equation 1 to show the relationship between life expectancy and the selected explanatory variables. The estimation equation will thus assume the following form:

$$
\begin{aligned}
& E X P E C T_{t}=45.49399 \quad 0.04523 G D P_{t}+1.38938 C P I_{t} \quad 2.67343 A G R_{t}+4.07996 P O P_{t} \\
& 0.96583 \mathrm{DEP}_{t}+_{t}
\end{aligned}
$$

According to the empirical results in table 3, economic growth (GDP) is negatively related to life expectancy (EXPECT) at 0.841565 significance level in Zimbabwe. Even though the result on the relationship is not statistically significant, the inverse relationship suggests that a 1 per cent increase in GDP reduces life expectancy by approximately 0.04523 per cent in Zimbabwe. Surprisingly, the relationship turned out to be negative and this goes against economic theory. However, the negative sign must be a reflection of what is currently happening in Zimbabwe. Economic growth has been rising steadily since the formation of the unity government in 2009 but unemployment and poverty rates are still disturbingly high. Revenue from natural resource wealth has not been used productively and it does not benefit the general population. Many people still do not have the financial resources to access proper medical facilities and also to have proper meals which could improve their standard of living.

Empirical results also suggest a positive relationship between inflation (CPI) and life expectancy in Zimbabwe. The positive impact of CPI on life expectancy is statistically significant at a 2.049684 significance level. According to the results, a percentage increase in CPI would increase life expectancy by approximately 1.38938 per cent. Though this result is statistically significant, this relationship between CPI and life expectancy in Zimbabwe is contrary to theory. Economic theory assumes life expectancy to decrease as people struggle to afford goods and services due to inflation. However, it should be noted that Zimbabwe imports most of its consumer and some of its medical goods. Many of these goods are imported from South Africa and they also contribute heavily to inflation (in form of imported inflation). Thus the more Zimbabwe imports these goods the greater the chances of increases in inflation. On the other hand, when Zimbabwe imports more consumer and medical goods, it would mean that people in Zimbabwe will have a better standard of living and also have medication when they are sick. In this case, a positive relationship can be established; the more Zimbabwe imports, the higher the inflation rate (through imported inflation), and the better the standard of living. 
Results also revealed a negative relationship between an increase in agricultural land as a percentage of total land (AGR) and life expectancy. The result which is statistically significant at 4.152104 proposes that a percentage increase in AGR reduces life expectancy by approximately 2.673434 per cent in Zimbabwe. The result is applicable to the Zimbabwe agricultural programme where people are given land in places that are underdeveloped. These places lack basic infrastructure, have no medical facilities and the roads are inaccessible. Moreover, there is poor sanitation, no piped water and consequently the areas are susceptible to water borne diseases such as cholera, dysentery and many other diseases. As a result of this the mortality rate of these areas should be high and this negatively affects life expectancy.

A positive relationship between population growth (POP) and life expectancy in Zimbabwe is also revealed by empirical results in this study. With a strong statistical significance of 13.91567 , the result suggests that a percentage rise in POP increases life expectancy by approximately 4.079958 per cent. This could be economically reasonable for a labour intensive country like Zimbabwe that an increase in the country's population increases the labour force which may have both direct and indirect effects on the overall wellbeing and standard of living of Zimbabweans.

Empirical results also revealed a negative relationship between the growth in dependency ratio (DEP) and life expectancy in Zimbabwe. With a statistical significance of 2.127434 , a percentage increase in DEP reduces life expectancy by approximately 0.965832 per cent. This relationship makes economic sense because an increase in the dependency ratio increases the economic and financial burden on the breadwinner, affecting the standard of living and subsequently the years lived.

\section{Diagnostic Tests}

It is imperative to note that the empirical results shown in Table 3 revealed a slightly low Durbin-Watson statistic of 1.867022 which may suggests a low possibility of serial correlation. In spite of this, the study performs diagnostic checks to test for serial correlation (Lagrange Multiplier) and heteroskedacity (White test). Serial correlation test results are presented in Table 4.

Table 4. Breusch-Godfrey (BG) Serial Correlation LM Test

\begin{tabular}{llll}
\hline F-statistic & 18.34709 & Probability & 0.075004 \\
\hline Obs*R-squared & 22.00806 & Probability & 0.076117 \\
\hline
\end{tabular}

The BG test for serial correlation which is more powerful than the Durbin-Watson test showed that there is no serial correlation in the residuals. The LM Test showed a probability of 0.076117 hence the null hypothesis of no serial correlation can be accepted.

A test for heteroskedesticity was also conducted using the White test with no cross terms. The presence of heteroskedesticity means the model has some misspecifications hence conclusive results cannot be derived from such a model. Results on heteroskedesticity are presented in Table 5.

Table 5. White Heteroskedasticity Test

\begin{tabular}{llll}
\hline F-statistic & 1.534943 & Probability & 0.172503 \\
\hline Obs*R-squared & 13.93946 & Probability & 0.175771 \\
\hline
\end{tabular}

The White test for heteroskedesticity produced a CH-sq of 13.93946 at a probability of 0.175771 . The high probability suggests that the null hypothesis of no heteroskedesticity or no misspecification will thus not be rejected. Therefore, the model does not suffer from any misspecifications hence can be relied on and conclusions thereof. The diagnostic checks performed justified the suitability of the model, that is, there is no serial correlation and no heteroscedasticity. Therefore, results from this paper can be relied on. Compelling conclusions on the relationship between life expectancy and the selected explanatory variables can be deduced and applicable policies can be safely formulated. 
This study also tested for stability using the Ramsey RESET (Regression Specification Error Test) and the CUSUM tests. The Ramsey's RESET test detects specification errors in an equation which was known a priori to be misspecified but which nonetheless gave satisfactory values for all the more traditional test criteria such as goodness of fit, test for first order serial correlation and high t-ratios (Ramsey and Alexander, 1984). The RESET test was applied with 1 fitted term included in the test regression and results are presented in Table 6.

Table 6. Ramsey RESET Test

\begin{tabular}{llll}
\hline F-statistic & 0.000863 & Probability & 0.976721 \\
\hline Log likelihood ratio & 0.001031 & Probability & 0.974382 \\
\hline
\end{tabular}

The high probability in the RESET test result shows that there are no specification errors, that is, the estimators are not biased and inconsistent. Therefore, conventional inference procedures in this study are validated.

The subsequently performed CUSUM stability test is based on the cumulative sum of the recursive residuals which suggests that residuals outside the standard error bands indicate instability in the parameters of the equation. This option plots the cumulative sum together with the 5 per cent critical lines. According to Brown et al. (1975) the test suggests parameter instability if the cumulative sum goes outside the area between the two critical lines. Results for the CUSUM test performed in this study are shown in Figure 4.

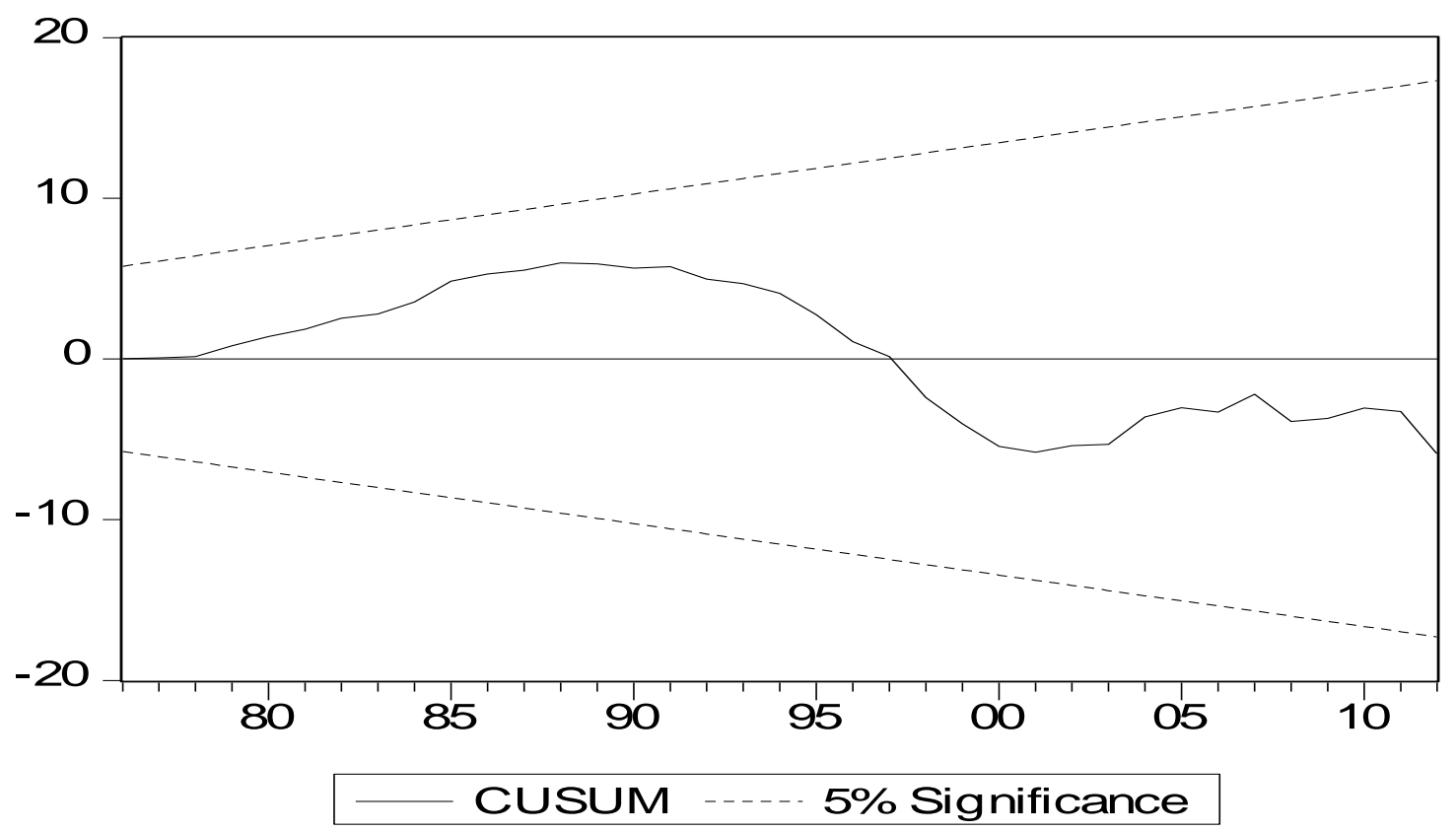

Figure 4. CUSUM Test Results

The CUSUM test result in Figure 4 suggests parameter stability since the cumulative sum is between the two 5 per cent critical lines. This suggests that inferences from the model used in this study can be relied on.

\section{CONCLUSION}

This study examined the impact of economic growth, inflation, increase in land allocated for agriculture, population growth and the dependency ratio on life expectancy over the 1970 to 2012 period in Zimbabwe. Trends in life expectancy where assessed with the study period divided into five decades, these are: 1970 to 1979,1980 to 1989, 1990 to 1999, 2000 to 2009 and finally 2010 to 2012. The study revealed that Zimbabweans lived longer in the first decade after independence (1980 to 1989) relative to the preceding and succeeding decades. Decades subsequent to the 1980 to 1989 decade recorded a decline in life expectancy. The least average life expectancy for the period of study was recorded in the 2000 to 2009 decade and was attributed to the political and economic crisis 
in Zimbabwe. Comparisons in this study revealed that Zimbabweans lived longer than most SADC countries except in the 2000 to 2009 decade when Zimbabweans lived less than all the SADC countries analysed. It was also discovered that female Zimbabweans lived longer than their male counterparts until the year 2001 when male Zimbabweans started to live longer than female Zimbabweans.

Empirical estimations in this paper revealed results that are partly contradictory and partly compatible with economic theory. It was discovered in this study that economic growth, inflation and population growth all have a positive relationship with life expectancy in Zimbabwe. This implies that an increase in each of these three variables will increase life expectancy in the country. Even though the impact of population growth could be argued to be compatible with economic theory, the result on the former two explanatory variables is strongly discordant with the common economic theoretical dictates. This therefore justifies the need for further research on the relationship between these variables in Zimbabwe.

Results also revealed that increases in both agricultural land and dependency ratio have a negative effect on life expectancy in Zimbabwe. That is, increases in these explanatory variables reduce life expectancy in Zimbabwe. These results can be justified because countries that have high levels of life expectancy moved from agriculture to industrial revolution centuries ago. Zimbabwe should therefore move with current global trends of industrialisation as opposed to agriculture revolution. Regarding the dependency ratio, an increase in the variable creates an economic and financial burden on the breadwinner, affecting the standard of living and subsequently the years lived.

\section{AUTHOR INFORMATION}

Genius Murwirapachena is a $\mathrm{PhD}$ (Economics) candidate at the Nelson Mandela Metropolitan University, South Africa. His research interests are Public finance, Environmental economics, Labour economics and Macroeconomics. Email: murwiragenius@gmail.com.

Courage Mlambo is a $\mathrm{PhD}$ (Economics) candidate at the University of Fort Hare's School of Business Management and Economics, South Africa. E-mail: mlamboct@gmail.com.

\section{REFERENCES}

Barford, A., Dorling, D., Smith, G.D., \& Shaw, M. (2006). Life Expectancy: Women Now on Top Everywhere. $B M J, 332: 808$

Barlow, R., \& Vissandjee B. (1999). Determinants of National Life Expectancy. Rev Can Etudes Dev, 20(1): 9 - 29

Bergh, A., \& Nilsson, T. (2010). Good for Living? On the Relationship between Globalization and Life Expectancy. World Development, 38(9): 1191-1203

Brown, R. L., Durbin, J., \& Evans, J. M. (1975). Techniques for Testing the Constancy of Regression Relationships over Time. Journal of the Royal Statistical Society, Series B, 37, 149-192.

Chapman, G., Hansen, K.S., Jelsma, J., Ndhlovu, C., Piotti, B., Byskov, J., \& Vos, T. (2006). The Burden of Disease in Zimbabwe in 1997 as measured by Disability adjusted Life Years lost. Tropical Medicine and International Health, 11(5): 660-671

Dickey, D.A., \& Fuller, W.A. (1979). Distribution of the Estimators for Autoregressive Time Series with a Unit Root. Journal of the American Statistical Association, 74, 427-431.

Griffith, F. (2001). The Impact of HIV/AIDS on Adult Mortality in Zimbabwe. Population and Development Review, 27 (4): 771-780.

Hallett, T.B., Gregson, S., Dube, S.E., Mapfeka, S., Mugurungi, O., \& Garnett, G.P. (2011). Estimating the Resources Required in the Roll-Out of Universal Access to Antiretroviral Treatment in Zimbabwe. Sex Transm Infect, 87:621-628.

Judge, K. (1995). Income Distribution and Life Expectancy: A Critical Appraisal. BMJ, 311: 1282 - 1285

Lin, R.T., Chen, Y.M., Chien, L.C., \& Chan, C.C. (2005) Political and Social Determinants of Life Expectancy in Developing Countries. Retrieved: http://www.biomedcentral.com/1471-2458/12/85/prepub

Mahfuz, K. (2008). Determinants of Life Expectancy in Developing Countries. J Dev Areas, 41(2): 185 - 204

Mathers, C.D., Sadana, R., Salomon, J.A., Murray, C.J.L., \& Lopez, A.D. (2001). Healthy Life Expectancy in 191 Countries, 1999. World Health Report, Lancet: 357 
Phillips, P.C.B., \& Perron, P. (1988). Testing for a Unit Root in Time Series Regression. Biometrika, 75, 335-346. Ramsey, J. B., \& Alexander, A. (1984). The Econometric Approach to Business-Cycle Analysis Reconsidered. Journal of Macroeconomics, 6, 347-356

Shaw, J.W., Horrace, W.C., \& Vogel, R.J. (2005). The Determinants of Life Expectancy: An Analysis of the OECD Health Data. Southern Economic Journal, 71(4): $768-783$

One in New 'Healthy Life' System. Press Release, Washington, D.C. and Geneva, Switzerland

Williamson, J.B., \& Boehmer, U. (1997). Female Life Expectancy, Gender Stratification, Health Status, and Level of Economic Development: A Cross-National Study of Less Developed Countries. Soc. Sci. Med, 45(2): 305-317

World Bank, (2013). Development indicators. Washington DC: World Bank

World Health Organisation [WHO], (2005). WHO Issues New Healthy Life Expectancy Rankings: Japan Number

Yikoniko, S. (2012, August, 25). Zimbabwe's Life Expectancy Up. Sunday Mail, Retrieved: http://www.sundaymail.co.zw/index.php?option=com 


\section{NOTES}

